\title{
LINGUISTIC AND COUNTRY STUDIES LEARNER'S DICTIONARY FOR MONGOLIAN CITIZENS: SPECIFICS OF PRESENTING THE MATERIAL
}

\author{
Aleksandr S. Mamontov \\ Pushkin State Russian Language Institute, Moscow, Russia \\ Enkhtuyaa Tsedendorzhiyn \\ Institute of Cognitive Linguistics, Ulaanbaatar, Mongolia \\ Vera V. Boguslavskaya \\ Pushkin State Russian Language Institute, Moscow, Russia
}

\begin{abstract}
The article is devoted to the principles of nationally oriented lexicography - a new direction in Russian studies. Using the example of nationally oriented linguistic and country studies learner's dictionary project, the paper shows that it can be created on the basis of the Russian linguistic and country studies dictionary by adding Mongolian material to its content and by comparing lexical backgrounds of the same culture-specific concepts in two linguistic cultures. The purpose of the nationally oriented linguistic and country studies learner's dictionary - the explication of the cultural component of the language unit semantics, taking into account the specifics of the national culture and the language of the addressee at the same time and taking into account the stage of learning - is reflected in the content and structure of the dictionary in general and dictionary entries in particular. Selecting nominative units and providing vocabulary objectivity are determined by the addressee's communicative needs. The author uses the methods of semantization of lexical units adopted in educational lexicography and determined by the specifics of both the material and the addresse. The paper provides the characteristics of techniques that ensure compliance with the proportions in using target and native languages. The draft dictionary presented in the article is able to serve as a "starting point" in creating a new type of dictionaries and further developing fundamentals of the theory of nationally oriented educational linguistic and cultural lexicography in relation to the needs of teaching Russian as a foreign language in the absence of the language environment.

Key words: nationally oriented dictionary, linguistic and country studies dictionary, the Mongolian language, the Russian language, intercultural communication, linguocultureme, linguistic culture, lexicography.

Citation. Mamontov A.S., Tsedendorzhiyn E., Boguslavskaya V.V. Linguistic and Country Studies Learner's Dictionary for Mongolian Citizens: Specifics of Presenting the Material. Vestnik Volgogradskogo gosudarstvennogo universiteta. Seriya 2, Yazykoznanie [Science Journal of Volgograd State University. Linguistics], 2019, vol. 18, no. 1, pp. 74-85. (in Russian). DOI: https://doi.org/10.15688/jvolsu2.2019.1.6
\end{abstract}

\section{ЛИНГВОСТРАНОВЕДЧЕСКИЙ УЧЕБНЫЙ СЛОВАРЬ ДЛЯ МОНГОЛЬСКИХ ГРАЖДАН: СПЕЦИФИКА ПРЕДСТАВЛЕНИЯ МАТЕРИАЛА}

\author{
Александр Степанович Мамонтов
}

Государственный институт русского языка им. А.С. Пушкина, г. Москва, Россия 


\section{Энхтуяа Цэдэндоржийн}

Институг когнитивной лингвистики, г. Улан-Батор, Монголия

\section{Вера Васильевна Богуславская}

Государственный институт русского языка им. А.С. Пушкина, г. Москва, Россия

Аннотация. В статье обсуждаются принципы национально ориентированной лексикографии - нового направления в отечественной русистике. На примере проекта национально ориентированного лингвострановедческого учебного словаря показано, что его создание возможно на базе русского лингвострановедческого словаря посредством добавления к содержанию монголоязычного материала и на основе сопоставления лексического фона одной и той же реалии в двух лингвокультурах. Цель национально ориентированного лингвострановедческого учебного словаря заключается в экспликации культурного компонента семантики языковых единиц с учетом специфики национальной культуры и языка адресата одновременно, а также с учетом этапа его обучения. Она находит отражение в содержании и структуре создаваемого словаря и словарных статей. Отбор номинативных единиц и обеспечение объективности словника обусловлены коммуникативными потребностями адресата. Одновременно использованы принятые в учебной лексикографии и определяемые спецификой как материала, так и адресата приемы семантизации лексических единиц. Охарактеризованы приемы, обеспечивающие соблюдение пропорций в использовании изучаемого и родного языков. Представленный в статье проект словаря способен послужить «отправной точкой» в создании словарей нового типа и в дальнейшей разработке основ теории национально ориентированной учебной лингвострановедческой лексикографии применительно к нуждам преподавания РКИ в условиях отсутствия языковой среды.

Ключевые слова: национально ориентированный словарь, лингвострановедческий словарь, монгольский язык, русский язык, межкультурная коммуникация, лингвокультурема, лингвокультура, лексикография.

Цитирование. Мамонтов А. С., Цэдэндоржийн Э., Богуславская В. В. Лингвострановедческий учебный словарь для монгольских граждан: специфика представления материала // Вестник Волгоградского государственного университета. Серия 2, Языкознание. - 2019. - Т. 18, № 1. - C. 74-85. - DOI: https://doi.org/10.15688/ jvolsu2.2019.1.6

\section{Введение}

С конца 70-х гг. прошлого века и по сегодняшний день лингвострановедческие словари оказывали и продолжают оказывать помощь в обучении русскому языку как средству межкультурной коммуникации, ибо наряду с языком учащиеся постигают соответствующую культуру во всем ее многообразии [Мамонтов, 2000]. У истоков создания первых в истории отечественного языкознания лингвострановедческих словарей стояли представители научной школы Государственного института русского языка им. А.С. Пушкина во главе с замечательным советским, российским языковедом Валерием Вениаминовичем Морковкиным (1940-2016), ученые, которые и сегодня вносят свой неоценимый вклад в развитие отечественной русистики. Основу лингвострановедческих словарей (далее - ЛС) составляли слова и словосочетания русского языка, называющие характерные для советской действительности явле- ния общественной жизни и культуры. Например, в словаре «Народное образование в СССР» (Денисова) описаны общие представления так называемого «среднего русского» о дошкольных учреждениях, средней и высшей школах, нашедшие отражение в лексике. Полученные благодаря таким словарям знания способствовали более адекватному пониманию иностранными обучающимися русской речи и одновременно давали им возможность продуцировать высказывания в разных реальных ситуациях общения с носителями русского языка, нивелировать возникающие в процессе общения трудности, связанные в первую очередь с интерференцией на всех ее уровнях. По своему содержанию изданные отечественные и зарубежные лингвострановедческие словари см., например: (Денисова; Фелицына, Мокиенко; Чернявская 1; Collins; Cowie; IOD; NEB; ODEE; OGBAC и др.) являются универсальными, базовыми, адресованными «иностранцу вообще», которого, однако, не существует. 
Сегодня на базе достижений современной теории и практики обучения языку возникает возможность создания лингвострановедческих национально ориентированных учебных словарей, в которых учитывается специфика национальной культуры адресата, что увеличивает эффективность обучения иностранным языкам (подробно об этом см.: [Морковкин, 1986]).

В настоящее время в Государственном институте русского языка им. А.С. Пушкина реализуется научно-исследовательский проект по созданию национально ориентированного лингвострановедческого учебного словаря для монгольских граждан «Обучение русскому языку как средству межкультурной коммуникации с учетом национальной культуры адресата», исполнителями которого являются авторы настоящей статьи. Словарь создается с опорой на работы специалистов в области русской и монгольской лексикографии и лингвокультурологии (в частности: [Бахтикиреева, 1995; Мамонтов, Цэдэндоржийн, Богуславская, 2018; Морковкин, 1986; Синячкин, 2010; Энхтуяа, 2015]). При этом авторы проекта считают, что его целесообразно создавать на базе уже изданного оригинального ЛС (см. ниже). Подобный подход, с нашей точки зрения, способен стать гарантом как достоверности, так и информативной достаточности содержания будущего словаря.

\section{Принципы \\ национально ориентированной лексикографии}

Национально ориентированная лексикография представляет собой новую научную дисциплину, в прикладном аспекте изучающую взаимодействие языка и культуры. Объектом исследованиий, проводимых в рамках этой дисциплины, являются национально ориентированные лексикографические источники, а предметом - методология их сопоставительного анализа, нацеленного на поиск оптимальной модели построения словаря, ориентированного на обучение любому языку как средству межкультурной коммуникации в соответствии с известным в лингводидактике принципом учета особенностей родной культуры адресата [Верещагин, Костомаров, 1990].
Нельзя не признать, вслед за В.В. Морковкиным [Морковкин, Курочкина, 1982], что национально ориентированная лексикография ставит во главу угла решение таких задач, как:

1) установление специфики адресата национально ориентированного ЛС;

2) выбор ЛС, на основе которого можно создать его национально ориентированный вариант;

3) формулирование требований, которым должен соответствовать национально ориентированный ЛС;

4) определение структуры и объема содержания национально ориентированного ЛС.

Адресат национально ориентированного учебного ЛС не столь широк по сравнению с адресатом словарей других типов (толковых, лингвострановедческих и т. д.). Как правило, это студенты филологического профиля - будущие учителя-русисты, переводчики, лингвисты, хотя и не филологи, в зависимости от поставленных перед ними целей и задач, также могут использовать такой словарь. Полагаем, что для студентов-филологов как начального, так продвинутого этапов обучения наиболее целесообразно подобрать в качестве основы для создания национально ориентированного учебного словаря не монотематический, а политематический лингвострановедческий словарь, поскольку словник монотематического словаря, на наш взгляд, более специализирован и уровень языковой подготовки обучающихся не позволяет им в полной мере овладеть всем его содержанием, что, однако, не мешает им пользоваться монотематическим ЛС как вспомогательным. Одновременно авторам национально ориентированного ЛС необходимо принимать во внимание тот факт, что не все политематические ЛС способны выступать в качестве основы для создания национально ориентированного словаря. Проведенный нами анализ разных ЛС (см. например: [Энхтуяа, 2015, с. 32-39]) позволил прийти к выводу, что создание лингвострановедческого учебного словаря для монгольских граждан оптимально на базе «Лингвострановедческого словаря национальных реалий России», составленного Т.Н. Чернявской и опубликованного в 1999 году (Чернявская 2). Во-первых, словник этого лексикографического издания включает около 1000 единиц, знание которых не- 
обходимо при изучении русского языка как средства межкультурной коммуникации. Во-вторых, «Лингвострановедческий словарь национальных реалий России», несмотря на свою без малого двадцатилетнюю историю, отражает новый этап в развитии отечественной лингвострановедческой лексикографии, в частности, в нем использованы новые способы семантизации фоновых знаний, отсутствующие в других словарях подобного типа.

Национально ориентированный вариант ЛС, кроме признаков, свойственных всем словарям этого типа, реализует набор отличительных признаков. Так, словарь, ориентированный на носителей монгольского языка, в некоторых своих разделах является двуязычным; семантизация лексики в нем проводится в русле сопоставительного лингвострановедения с учетом специфики монгольской национальной культуры, а также с активным использованием возможности наглядного представления материала. В качестве еще одного общедидактического принципа выступает принцип посильности: поскольку текст словарной статьи должен быть доступным для восприятия студентами разных уровней владения русским языком, то наиболее эффективной следует, по нашему мнению, считать семантизацию лексики с применением родного языка адресатов, а также обращение к аутентичным материалам с параллельными текстами на монгольском языке, что позволит использовать словарь студентам как начального, так и продвинутого уровней обучения.

Лингвометодическая категория адресата обусловливает требование учитывать в процессе преподавания иностранного языка особенности родного языка учащихся. Как показывает практика, родной язык способен обеспечивать желаемый перенос определенных навыков и умений в речь на изучаемом языке, следовательно, перенос необходимо по возможности стимулировать. Однако родной язык выступает и источником интерференции, затрудняющей овладение речевыми навыками и умениями на неродном языке, а следовательно, интерференцию необходимо прогнозировать и предотвращать. В то же время лингвокультурологические знания о России, равно как и коммуникативные навыки, приобретенные обучающимся на родине, должны стать объектом переноса и сохранения в целях их последующего совершенствования. Необходимо особо подчеркнуть, что искаженные сведения, а также неверное (интуитивное) отождествление фактов изучаемой и родной для студента лингвокультур, должны быть элиминированы, поскольку являются нежелательным источником лингвострановедческой интерференции [Верещагин, Костомаров, 1990, с. 94].

По нашему мнению, перекодирование оригинальной словарной статьи, а также подготовка комментариев и ссылок составляют лишь незначительную часть работы автора национально ориентированного ЛС. Центральным же элементом двуязычного текста статьи в таком ЛС следует считать сравнение ассоциаций, имеющихся у носителей русского и монгольского языков по отношению к сходной реалии. Поскольку именно это в большей степени способно обеспечить повышение эффективности семантизации. Такая работа создает возможности в полной мере представить те семные, в том числе и коннотативные различия, которые не могут быть эксплицированы в рамках не национально ориентированного учебного ЛС. Например, как известно, для русского человека береза является символом Родины, однако и стройную девушку в русской лингвокультуре нередко сравнивают с белой березой. В данной ситуации для монгола возникает затруднение в восприятии, поскольку в Монголии девушку принято сравнивать с ланью, а березы, которые растут на территории этой страны, по-видимому, в силу специфических природно-климатических условий имеют несколько иной, менее привлекательный вид: по высоте они значительно ниже российских, по форме их нельзя назвать стройными, по цвету они ближе к серому, чем к белому. Следовательно, для семантизации слова береза необходимо наглядно представить российскую реалию.

У носителя же русской лингвокультуры затруднение в восприятии вызовет, например, существующее в монгольской лингвокультуре сравнение женщины с весенним небом, означающее, что она «человек настроения» (подробно сравнение номинативных ассоциаций в русской и монгольской лингвокультурах представлено в [Энхтуяа, 2015, с. 150-151]). 
Данные примеры позволяют увидеть, как через сопоставление фоновых знаний эксплицируются различия между культурами [Guirdham, 1999]. Эти различия, к сожалению, не находят отражения в традиционных словарях, хотя в ситуациях реального общения незнание их зачастую служит причиной неадекватного восприятия информации. Таким образом, именно эксплицированное сравнение лексического фона должно являться одним из основных способов семантизации в национально ориентированном учебном ЛС. При этом сопоставление лексического фона необходимо проводить в строгом соответствии с теоретически и практически обоснованными параметрами, учитывающими: 1) наиболее известные произведения фольклора, литературы и изобразительного искусства, коррелирующие с заголовочной единицей, связанные с ней; 2) систему символов; 3) единицы языка и речи, имеющие связь с объектом: устойчивые сочетания, сравнения, тропы; 4) неординарные примеры словообразования на основе корня, присутствующего в слове-заголовке; 5) обозначения артефактов с использованием слова-заголовка.

Сопоставление лексических фонов при определении словника национально ориентированного учебного словаря является способом отбора лексических единиц - лингвокультурем [Воробьев, 1997], оценки их значимости для инофона. Существуют два известных лексикографам приема, открывающих возможность модифицировать контент семантизирующих текстов в целях достижения большего соответствия экспектациям конкретного адресата: прием так называемой «компарации» и прием «обзорно-страноведческого опережения».

Первый был разработан болгарским исследователем К. Андрейчиной [Андрейчина, 1977]. Данный прием реализуется посредством, во-первых, рассмотрения двух понятийно-эквивалентных номинативных единиц с точки зрения их семного состава, во-вторых, последующей фиксации эксплицированных совпадений / несовпадений, в-третьих, оформления полученного результата в виде дополнения к содержанию базовой русскоязычной словарной статьи. Такая процедура способствует преобразованию исходного материала в национально ориентированный учебный текст. Однако прием компарации обладает значимо- стью лишь в случае взаимодействия контактных культур [Jandt, 2000]. В случаях взаимодействия культур дистантных продуктивнее использовать второй прием. Он заключается в переходе от общего к частному, где под последним имеются в виду конкретные реалии.

Любое изъяснение лингвокультурем, как показано Е.М. Верещагиным и В.Г. Костомаровым [Верещагин, Костомаров, 1990, с. 85], должно сопровождаться средствами зрительной семантизации, имеющей ряд преимуществ перед вербальной, в частности, в плане, субъективно переживаемой достоверности и яркости впечатлений. Кроме того, невозможно игнорировать случаи полного отсутствия денотата в лингвокультуре инофона, где зрительная семантизация должна выступать в качестве приоритетной. Основными требованиями к зрительной семантизации в лингводидактике принято считать: 1) отражение всех существенных сторон обозначенного словом предмета или явления, 2) ориентацию на текст изъяснения, 3) доступность. Реализация первого требования способствует тому, что иллюстрация в словаре становится исчерпывающей. При ее выборе автор ограничен в возможности намека на ту или иную деталь в целях подсказки и в расчете на сообразительность инофона. Второе требование определяет жесткую привязку иллюстрации к изъяснению, что гарантирует взаимодополнение информации, заложенной и в иллюстрации, и в тексте изъяснения. То, что читателю непонятно в рисунке, становится понятным из изъяснения; то, что непонятно в изъяснении, становится очевидным при обращении к рисунку. Согласно третьему требованию, иллюстрация в ЛС должна быть доступной для восприятия. Это означает, что она не может быть выполнена в неадекватной для восприятия манере, отражающей мировидение того или иного художника, фотографа и т. д. и провоцирующей ее индивидуальное восприятие обучающимся. Кроме того, иллюстрация не должна иметь «подтекстового» значения, в частности, юмористического. Необходимо учитывать, что выбор между рисунком или фотографией обусловлен характером описываемого в тексте объекта. Если речь идет о деталях зрительного образа, то предпочтительнее фотографии, поскольку они способны производить более 
достоверное впечатление. В ЛС в первую очередь целесообразно использовать так называемые «научно-познавательные» иллюстрации, а к «художественно-образным» прибегать в особых случаях.

\section{Структура}

\section{национально ориентированного}

\section{лингвострановедческого словаря}

Структура создаваемого словаря включает: предисловие; оглавление; инструкцию для пользователя; перечень заголовочных единиц в алфавитном порядке с нумерацией страниц, где данные единицы были упомянуты впервые; базовую часть словаря, то есть словарные статьи, расположенные в вышеупомянутом порядке; перечень всех номинативных единиц в соответствии с темой и указанием нумерации страниц, где они зафиксированы; приложения.

Словник. Будучи ограниченными рамками настоящей статьи, мы намеренно опускаем описание особенностей словника «Лингвострановедческого словаря национальных реалий России», взятого нами в качестве основы национально ориентированного словаря, и переходим непосредственно к описанию словника, составленного нами для национально ориентированного лингвострановедческого словаря для монгольских граждан. Итак, перечень выбранных заголовочных единиц представлен в двух видах: 1) алфавитный с указанием номеров страниц, на которых они размещены; 2) тематический, содержащий не только заголовочные номинативные единицы, но и слова, являющиеся ключевыми для каждой словарной статьи (таким образом, по нашему мнению, открывается возможность расширения номенклатуры реалий, информацию о которых можно получить с помощью словаря). Внутри тематических групп слова располагаются по алфавиту с указанием номеров страниц, на которых они встречаются в словаре. Названия тематических групп переведены на монгольский язык, а заголовочные и другие номинативные единицы в перечне переводу не подлежат.

Тематические поля выделяются в соответствии с логикой составителей уже существующих идеографических и тематичес- ких словарей и исходя из конкретного материала. Прежде всего, выделены семантические поля, связанные с человеком и природными явлениями - теми сферами, где возможно прогнозирование культурологических лакун.

Приложения к национально ориентированному ЛС. В национально ориентированном ЛС авторы планируют продолжить традиции национальной монгольской лексикографии, предполагая в качестве приложений к словарю использовать исключительно страноведческий материал, в котором могут содержаться дополнительные сведения о стране изучаемого языка. По замыслу авторов, в формате приложений будут также представлены: 1) краткое изложение лингвострановедческой теории слова [Верещагин, Костомаров, 1980] и толкование понятия «лингвострановедение» [Верещагин, Костомаров, 1990]; 2) краткий курс истории Российского государства; 3) географическая карта Российской Федерации; 4) изображения всех видов городского транспорта, остановок всех наземных средств городского транспорта, станций метрополитена и наземного метро; 5) адреса главных московских и петербургских музеев и театров; 6) православный именинник. Приложения 1 и 2 будут даны на монгольском языке, остальные - на русском, но с переводом на монгольский язык.

Предисловие и инструкция по использованию национально ориентированного лингвострановедческого словаря. Согласно традициям монгольской лексикографии, в предисловии словарь кратко характеризуется с профессиональной точки зрения его ответственным редактором. Помимо этого в предисловии излагается краткая информация об авторах, их роли в создании словаря. Инструкция для пользователей содержит информацию о структуре словарной статьи, ее образец, описание приемов семантизации языкового материала с указанием цели их применения. Кроме того, в инструкции приведены перечень сокращенных слов и словосочетаний, перечень условных знаков, значение шрифтов разных размеров и других лексикографических знаков. Необходимо отметить, что и предисловие, и инструкция также даются на монгольском языке. 


\section{Содержание и структура словарной статьи}

национально ориентированного

лингвострановедческого словаря

Содержание словарных статей создаваемого нами национально ориентированного ЛС формируют статьи базового ЛС на русском языке и их переводы на монгольский язык. Полагаем, однако, что в перевод оригинальной статьи целесообразно добавить значимую для монгольского адресата информацию, способную обеспечить экспликацию лексического фона национальных реалий страны изучаемого языка. По нашему мнению, определение объема дополнительных сведений неразрывно связано с процессом сопоставления лексических фонов реалий двух лингвокультур.

Наполнение каждой статьи должно демонстрировать различия в восприятии того или иного факта культуры двух стран по ряду параметров: 1) роль и место в национальной лингвокультуре [Cushner, Brislin, 1995]; 2) функции в национальной лингвокультуре, включая возможность выступать в функции семантического предиката в предложении и быть одновременно предметом сопоставления (сравнения); 3 ) экспликация характеристик внешнего плана (размер, цвет, форма); 4) потенциальная сочетаемость; 5) представленность во фразеологических единицах, единицах афористического уровня, а также в прецедентных текстах [Hirsch, Kett, Trefil, 1988].

Структура статьи национально ориентированного лингвострановедческого учебного словаря включает следующие разделы: Заголовочная единица и ее грамматическая характеристика; Толкование заголовочной единицы и его перевод; Краткая энциклопедическая справка, ее перевод, частичное сопоставление некоторых признаков с признаками монгольских реалий; Изъяснение лексического фона заголовочной единицы, его перевод и сопоставление с лексическим фоном соответствующей реалии в монгольской культуре, выявление сходств и различий; Информация о наиболее устойчивых языковых единицах, связанных с реалией, обозначенной заголовочной единицей; Информация о наиболее известных фактах отражения реалии, обозначенной заголовочной единицей, в литературе, музыке, изобразительном искусстве; ее перевод; Рисунки, семантизирующие заголовочную единицу; Отсылочный материал.

Заголовочная единица и ее грамматическая характеристика. Заголовочной единицей словарных статей избирается вариант называния реалии, наиболее употребительный в речи. После заголовочной единицы приводятся другие варианты называния реалии в соответствии с уменьшением употребительности. Например, заголовочная единица «Большой театр», полное и официальное название, а также другие номинации - «Государственный академический Большой театр России», варианты: сокр. «ГАБТ», разг. «Большой». В качестве заголовочной единицы могут быть даны варианты наименования реалий, например: «Театр на Таганке», полное название «Московский театр драмы и комедии на Таганке» и разговорный вариант «Таганка».

Поскольку словник отражает преимущественно названия реалий, лингвистическое описание заголовка не является сложной. Подобно всем известным ЛС, в составляемом нами словаре заголовочная единица в дидактических целях вводится вместе с ударением, указанием формы падежа (родительного) и категории рода. В отдельных случаях предусмотрены и другие грамматические характеристики.

Заголовочная единица не нуждается в переводе на родной язык обучаемых, так как номинативные единицы словаря представляют собой лингвокультуремы по отношению к монгольской культуре.

Толкование заголовочной единицы и его nеревод. Для имен нарицательных дается толкование лексического понятия, например: азбука - совокупность букв, принятых в данной письменности, располагаемых в установленном порядке. Для имен собственных и реалий, обозначаемых датами, приводится энциклопедическое толкование, например: Амур - река на Дальнем Востоке, одна из крупнейших рек мира; 1147 г. - 1147 год год первого упоминания Москвы в летопи$c u$. Толкование обычно точное и нейтральное, оно не требует специального перевода, его содержание во многих случаях эквивалентно в обоих языках. 
Краткая энциклопедическая справка, ее перевод, частичное сопоставление некоторых признаков с признаками монгольских реалий. Этот раздел словарной статьи содержит информацию о месте и значении реалии в истории и культуре России. Хотя механизм восприятия студентами словарных сведений можно представить как «незнание знакомство - овладение», одного перевода энциклопедической справки недостаточно, необходимо отметить различия в ассоциациях по поводу одной и той же реалии у носителей разных языков и культур. Так, у монгольских студентов слово котелок вызывает ассоциации с посудой объемом не менее пяти литров, имеющей круглое дно и предназначенной для каждодневной варки пищи на огне в юрте, у носителей русского языка - ассоциации с посудой небольшого размера, предназначенной для приготовления пищи в туристическом походе. В энциклопедической справке к слову котелок в составляемом национально ориентированном словаре эти различия отмечаются.

Изъяснение лексического фона заголовочной единицы, его перевод и сопоставление с лексическим фоном соответствующцей реалии в монгольской культуре, выявление сходств и различий. В этом разделе словарной статьи дается информация о том, какие ассоциации возникают у носителей русского языка по поводу реалии, обозначенной заголовочной единицей, определяется статус данной реалии в обыденном сознании носителя языка. Приводятся сведения о поляризованности (если она имеет место) оценки реалии у носителей языка и культуры, принадлежащих к разным социальным слоям, об изменениях культурного фона реалии (изменения в понимании роли того или иного явления и отношения к нему в разных слоях российского общества в разные исторические периоды), например: отношение в современном российском обществе к Октябрьской револючии 1917 г., Гражданской войне и другим историческим событиям XX века.

Даются также сведения о сочетаемости, определяемой лексическим фоном заголовочной единицы, поскольку именно в устойчивых словосочетаниях часто можно выявить скрытый лексический фон.
Вводится информация о способности данной номинативной единицы выступать в качестве предмета сравнения и выполнять функцию семантического предиката в предложении, что также связано с лексическим фоном. Например: Ть Иван Сусанин! Сегодня я тепло оделся, как капуста.

Необходимо отметить, что данный раздел является наиболее важной частью словарной статьи. Именно через сопоставления ассоциаций в сознании носителей разных языков и культуры обнаруживается лексический фон, который каждый ЛС старается раскрыть разнообразными способами и приемами.

Информация о наиболее устойчивых языковых единицах, связанных с реалией, обозначенной заголовочной единицей. В качестве примера такой информации приведем фрагмент словарной статьи, посвященной Санкт-Петербургу. В ней отмечается, что в сознании русских слово Санкт-Петербург ассоциируется с пушкинскими строками из поэмь» «Медный всадник», романами Ф.М. Достоевского, стихами А.А. Блока и А.А. Ахматовой, с музыкой Д.Д. Шостаковича и В.П. Соловьева-Седого, а также образныли названиями города: северная Венеция, северная Пальмира, град Петра. Главная трудность представления материала в этом разделе заключается в необходимости перевода фразеологизмов и афоризмов, поиска для них эквивалентного толкования и выражения в монгольской культуре и языке.

Информация о наиболее известных фактах отражсения реалии, обозначенной заголовочной единицей, в литературе, музыке, изобразительном искусстве; ее перевод. Материалы этого раздела в основном имеют страноведческий характер, особых требований к их переводу на монгольский язык не предъявляется. Например, статья «Волга» предполагает обязательное упоминание о связанных с Волгой русских народных песнях, стихах Н.А. Некрасова, картинах И.Е. Репина и И.И. Левитана.

Рисунки, семантизирующие заголовочную единицу. В качестве средств зрительной семантизации заголовочных слов предлагаются работы русских художников, поскольку носителям монгольского языка, не знакомым с русской культурой, сложно воспроиз- 
водить признаки предметов, событий и явлений, отраженных в сознании носителя русского языка.

Отсылочный материал. В словарь вводятся отсылочные статьи. Они, как правило, на монгольский язык не переводятся.

Графическое оформление словарной статьи предполагает выделение жирным шрифтом заголовочных (с указанием ударения) и других ключевых слов словарных статей, выделение курсивом цитат, фразеологизмов, афоризмов и крылатых слов. Как утверждают специалисты, кегль шрифта текста на монгольском языке должен превосходить на пункт размер кегля шрифта текста на русском. В целях демонстрации различий в фоновых знаниях у представителей сопоставляемых культур в тексте на родном языке применяется выделение подчеркиванием.

Речевое оформление словарной статьи должно соответствовать, во-первых, уровню владения адресатом иностранным языком, что требует прежде всего тщательного отбора терминов, во-вторых, целям использования словаря: не только как справочного издания, но и в определенных обстоятельствах как учебного текста.

Ниже приводится образец словарной статьи из рубрики «Растительный мир»:

\section{(рисунокели)}

е́ль, -и, ж. (разг. ёлка, $-и, ж$,

Хвойное вечнозеленое дерево с кроной в форме конуса и длинными шишками.

Орой нь шовх шулуун бөгөөд гонзгойвтор боргочойтой менх ногоон шилмүүст мод.

Ель - одно из самых распространенных деревьев, растет практически по всей территории России. Растет ель очень долго, поэтому молодые еловые посадки тщательно охраняются лесоводческими хозяйствами. Ели часто растут в смешанном лесу́, но существуют и еловые леса. Еловый лестемный, в нем легко можно заблудиться.

Жодоо нь (гаиуур) нь ерген тархсан моддын нэг бегеед Орос орны бүхий л нутгаар ургана. Жодоо мод нь маш удаан ургах учир ойн аж ахуйнууд залуу суулгащыг нь чандлан хамгаалж байдаг. Жодоо нь ихэвчлэн холимог ойд ургах боловч дан жодоо модны ой бас байна. Ийм ой харанхуй байдаг тул хүн теерех нь амархан.

(картинка) Нередко для декоративных посадок в городах используют голубые ели с необычным цветом кроны.
Ер бусын оройтой иэнхэр гаиуурыг хот газрыг чимэх ногоон суулгаи болгон ашиглах нь багагуй.

(картинка) Еловая древесина используется в строительстве, в производстве бумаги.

Жодойг барилга болон ияас үйлдвэрлэхэд ашиглана.

Ёлка хороша в любое время года, но особенно она украшает зимний пейзаж, когда на её пышных зеленых ветках - лапах лежит белый серебристый снег. «Зимой и летом - одним цветом», - так говорится о ёлке в русской загадке.

Жодоо мод нь аль ч улиралд сайхан харагддаг ба ялангуяа саглагар ногоон мөчрууд нь мөнгөн иагаан иасанд дарагдан байх нь өвлийн дүр зургийг чимнэ. Өвөл зунгуй нэг өнгөөрөө гэж жодоо модны тухай орос оньсого хэлдэг.

(рисунок) Ель в России - новогоднее дерево, которое заранее покупают и ставят в доме, украшая специальными ёлочными игрушками. Под новогоднюю ёлку кладут подарки детям. Пушистую новогоднюю ёлку любят и взрослые и дети.

Жодоо нь Орос орны шинэ жилийн мод бөгөөд түүнийг урьдчилан худалдан авч гэртээ оруулан тусгай гаиуур модны тоглоомуудаар чимнэ. Чимсэн гаиуур модныхоо дор хуүхдүудэд зориулан бэлэг орхидог. Шинэ жилийн саглагар ногоон гаиуурт том жижиггуй дуртай.

(ноты) «В лесу родилась ёлочка».

(монгольский перевод песни)

\section{Заключение}

Создание национально ориентированного лингвострановедческого учебного словаря для монгольского адресата возможно на базе русского ЛС посредством добавления монголоязычного материала в тесной связи с материалом о монгольской культуре и на основе сопоставления лексического фона одной и той же реалии в двух лингвокультурах.

Как и все ЛС, национально ориентированный ЛС нацелен на экспликацию культурного компонента семантики языковых единиц с учетом специфики национальной культуры и языка адресата одновременно, а также этапа его обучения, что находит отражение в содержании и структуре создаваемого словаря.

Отбор номинативных единиц и обеспечение объективности словника обусловлены коммуникативными потребностями адресата. Поскольку словарные статьи призваны обеспечивать представление о своеобразии контактирующих, а по сути - дистантных по от- 
ношению друг к другу культур, в них приведены ассоциации, связанные с одной и той же реалией в разных лингвокультурах. Одновременно использованы принятые в учебной лексикографии и обусловленные спецификой как материала, так и адресата приемы семантизации лексических единиц. В пределах словаря материалы расположены в традиционной последовательности, к которой адресат привык со школьной скамьи.

При создании национально ориентированного ЛС релевантным является соблюдение пропорций в использовании изучаемого и родного языков. Родной для обучающихся язык и, соответственно, культура занимают в словаре существенное место, однако смещению акцентов препятствуют реализация в нем принципа адресата и цель создания словаря - обучение русскому языку, хотя словарь может также быть полезен и при обучении монгольскому языку. Перевод материалов на родной язык адресата предпочтителен в отдельных случаях, которые определяются лингвокультурным и дидактическим опытом составителей словаря, поскольку на сегодняшний день в монгольской русистике не существует научных исследований, позволяющих объективировать этот процесс. Думается, что практика использования национально ориентированного ЛС позволит в известной мере восполнить существующий пробел: представленный в статье проект словаря способен, по нашему мнению, послужить «отправной точкой» как в создании словарей нового типа, так и в дальнейшей разработке основ теории национально ориентированной учебной лингвострановедческой лексикографии применительно к нуждам преподавания РКИ в условиях отсутствия языковой среды, в частности в вузах Монголии.

\section{СПИСОК ЛИТЕРАТУРЫ}

Андрейчина К., 1977. Компарация семантических долей фона как прием в написании ориентированных статей лингвострановедческого словаря // Из опыта создания лингвострановедческих пособий по русскому языку / под ред. Е. М. Верещагина, В. Г. Костомарова, Ю. Е. Прохорова. М. : Изд-во Моск. ун-та. C. $148-155$.
Бахтикиреева У. М., 1995. Художественные функции лексики с национально-культурным компонентом семантики в романе Ч. Айтматова «И дольше века длится день» : автореф. дис. ... канд. филол. наук. М. 16 с.

Верещагин Е. М., Костомаров В. Г., 1980. Лингвострановедческая теория слова. М. : Русский язык. 320 с.

Верещагин Е. М., Костомаров В. Г., 1990. Язык и культура. Лингвострановедение в преподавании русского языка как иностранного. М. : Русский язык. 246 с.

Воробьев В. В., 1997. Лингвокультурология (теория и методы). М. : Изд-во РУДН. $331 \mathrm{c.}$

Мамонтов А. С., 2000. Язык и культура: сопоставительный аспект изучения. М. : ИЯ РАН. 183 с.

Мамонтов А. С., Цэдэндоржийн Э., Богуславская В. В., 2018. Национально-ориентированный. двуязычный словарь как средство обучения межкультурной коммуникации граждан Монголии // Пересекая границы: межкультурная коммуникация в глобальном контексте : Материалы I Междунар. науч.-практич. конф. (Гос. ИРЯ им. А.С. Пушкина, 1416 февраля 2018 г.). М. : ГИРЯП. С. 188-189.

Морковкин В. В., 1986. О базовом лексикографическом умении // Учебники и словари в системе средств обучения русскому языку как иностранному. М. : Русский язык. С. 102-117.

Морковкин В. В., Курочкина И. М., 1982. О страноведческом потенциале лексического ядра современного русского языка // Словари и лингвострановедение. М. : Русский язык. С. 62-72.

Синячкин В. П., 2010. Общечеловеческие ценности как инструмент анализа языкового сознания членов общества // Вестник РУДН. Серия: Теория языка. Семиотика. Семантика. №2. С. 62-67.

Энхтуяа Ц., 2015. Язык и культура: основы национально-ориентированной лексикографии (с позиции носителя монгольского языка). М. : Гос. ИРЯ им. А.С. Пушкина. 200 с.

Cushner K., Brislin R. W., 1995. Intercultural Interactions. London : Sage. 365 p.

Guirdham M., 1999. Communicating Across Cultures. London : Macmillan press. 383 p.

Hirsch E. D., Kett J. F., Trefil J., 1988. The Dictionary of Cultural Literacy. What Every American Needs to Know. New York : Random House, Inc. 254 p.

Jandt F., 2000. Intercultural Communication: An Introduction. Newbury Park : Sage. 255 p.

\section{ИСТОЧНИКИ И СЛОВАРИ}

Денисова - Денисова М. А. Народное образование в СССР. Лингвострановедческий словарь / под 
ред. Е. М. Верещагина, В. Г. Костомарова. М. : Русский язык, 1981.271 с.

Фелицына, Мокиенко - Фелицына В. П., Мокиенко В. М. Русские фразеологизмы: Лингвострановедческий словарь / под ред. Е. М. Верещагина, В. Г. Костомарова. М. : Русский язык, 1990. $222 \mathrm{c.}$

Чернявская 1 - Чернявская Т. Н. Художественная культура СССР: Лингвострановедческий словарь. М. : Русский язык, 1984. 353 с.

Чернявская 2 - Лингвострановедческий словарь национальных реалий России / сост. Т. Н. Чернявская [и др.]. М., 1999. 59 с.

Collins - Collins. The Times English Dictionary \& Thesaurus. Glasgow : Harper Collins, 2000. $1397 \mathrm{p}$.

Cowie-Cowie A. P. English Dictionaries for Foreign Leaners: History. Oxford : Clarendon Press, 1999. $232 \mathrm{p}$.

$I O D$ - Illustrated Oxford Dictionary. Oxford : Oxford University Press, 2000. 1008 p.

$N E B$ - The New Encyclopedia Britannica. In 29 vols. Chicago ; Auckland ; London ; Madrid ; Manila ; Paris ; Rome ; Seol ; Sydney ; Tokyo ; Toronto, 1993-1994.

$O D E E$ - The Oxford Dictionary of English etymology / C.T. Onions, G. W. S. Friedrichsen, R. W. Burchfield (eds.). Oxford : Clarendon Press, 1996. $1040 \mathrm{p}$.

$O G B A C$-Oxford Guide to British and American Culture / J. Crowther. Oxford : Oxford University Press, $1999.600 \mathrm{p}$.

\section{REFERENCES}

Andreychina K., 1977. Komparatsiya semanticheskikh doley fona kak priyom $v$ napisanii orientirovannykh statey lingvostranovedcheskogo slovarya [Comparison of Semantic Parts of the Context as a Method in Writing Linguistic and Cultural Dictionary's Entries]. Iz opyta sozdaniya lingvostranovedcheskikh posobiy po russkomu yazyku. Moscow, Izd-vo Moskovskogo universiteta, pp.148-155.

Bakhtikireeva U.M., 1995. Khudozhestvennye funktsii leksiki s natsionalno-kulturnym komponentom semantiki v romane Ch. Aytmatova "I dolshe veka dlitsya den": avtoref. dis. ... kand. filol. nauk [The Artistic Functions of the Vocabulary with the National and Cultural Semantic Component in the Novel of Ch. Aytmatov "The Day Lasts more than a Hundred Years". Cand. philol.sci.abs.diss.]. Moscow. $16 \mathrm{p}$.

Vereshhagin E.M., Kostomarov V.G., 1980. Lingvostranovedcheskaya teoriya slova
[Linguistic and Regional Studies Theory of Words]. Moscow, Russkiy yazyk Publ. 320 p. Vereshchagin E.M., Kostomarov V.G., 1990. Yazyk $i$ kultura. Lingvostranovedenie $v$ prepodavanii russkogo yazyka kak inostrannogo. [Linguistic and Cultural Studies in Teaching Russian as a Foreign Language]. Moscow, Russkiy yazyk Publ. 246 p.

Vorobyov, V.V., 1997. Lingvokulturologiya (teoriya $i$ metody). [Linguoculturology: Theory and Methods]. Moscow, Izd-vo RUDN. 331 p.

Mamontov A.S., 2000. Yazyk i kultura: sopostavitelnyy aspekt izucheniya [Mamontov A. S., 2000. Language and Culture: a Comparative Aspect of Learning]. Moscow, Iya RAN Publ. 183 p.

Mamontov A.S., Tsedendorzhiyn E., Boguslavskaya V.V., 2018. Natsionalno-orientirovannyy dvuyazychnyy slovar kak sredstvo obucheniya mezhkulturnoy kommunikatsii grazhdan Mongolii [The Nationally Oriented Bilingual Dictionary as a Means of Teaching Mongolian Citizens Crosscultural Communication]. Peresekaya granitsy: mezhkulturnaya kommunikatsiya v globalnom kontekste: Materialy I Mezhdunarodnoy nauchno-prakticheskoy konferentsii (Gos. IRYa im. A.S. Pushkina, 14-16 fevralya 2018 g.) [Proceedings of the International Scientific and Practical Conference Crossing Borders. The Pushkin State Museum Of Fine Arts, Moscow, Russia, 14 - 16Feb 2018]. Moscow, GIRYAP Publ., pp.188-189.

Morkovkin V.V., 1986. O bazovom leksikograficheskom umenii [About Basic Lexicographical Skills]. Uchebniki i slovari v sisteme sredstv obucheniya russkomu yazyku kak inostrannomu. Moscow, Russkiy Yazyk Publ., pp.102-117.

Morkovkin V.V., Kurochkina, I.M., 1982. O stranovedcheskom potentsiale leksicheskogo yadra sovremennogo russkogo yazyka [About Linguistic and Country Studies Potential of the Modern Russian Language Lexical Core]. Slovari i lingvostranovedenie. Moscow, Russkiy Yazyk Publ., pp. 62-72.

Sinyachkin V.P., 2010. Obshchechelovecheskie tsennosti kak instrument analiza yazykovogo soznaniya chlenov obshchestva [Universal Values as a Tool for the Analysis of the Linguistic Consciousness of Society Members]. Vestnik RUDN. Seriya: Teoriya yazyka. Semiotika. Semantika [RUDN Journal of Language Studies. Semiotics. Semantics], no. 2, pp. 62-67.

Enkhtuyaa Ts., 2015. Yazyk i kultura: osnovy natsionalno-orientirovannoy leksikografii (s pozitsii nositelya mongolskogo yazyka): monografiya [Language and Culture: the Basics 
of Nationally-Oriented Lexicography (from a Mongolian Native Speaker: Monograph]. Moscow, Pushkin State Russian Language Institute Publ. 200 p.

Cushner K., Brislin R.W., 1995. Intercultural Interactions. London, Sage. 365 p.

Guirdham M., 1999. Communicating Across Cultures. London, Macmillan Press. 383 p.

Hirsch E.D., Kett J.F., Trefil J., 1988. The Dictionary of Cultural Literacy. What Every American Needs to Know. New York, Random House, Inc. 254 p.

Jandt F., 2000. Intercultural Communication: An Introduction. Newbury Park, Sage. 255 p.

\section{SOURCES AND DICTIONARIES}

Denisova M.A. Narodnoe obrazovanie v SSSR. Lingvostranovedcheskiy slovar [National Education in the USSR. The Linguistic and Country Studies Dictionary]. Moscow, Russkiy yazyk Publ., 1981. 271 p.

Felitsyna V.P., Mokienko V.M. Russkie frazeologizmy: Lingvostranovedcheskiy slovar [Russian Phrazeology. Linguistics and Country Studies Dictionary]. Moscow, Russkiy yazyk Publ., 1990. $222 \mathrm{p}$.
Chernyavskaya T.N. Khudozhestvennaya kultura SSSR: Lingvostranovedcheskiy slovar. [The Artistic Culture of the USSR: Linguistics and Country Studies Dictionary]. Moscow, Russkiy yazyk Publ., 1984. 353 p.

Chernyavskaya T.N. Lingvostranovedcheskiy slovar natsionalnykh realiy Rossii [Linguistics and Country Studies Dictionary of Russia's CultureSpecific Concepts]. Gosudarstvennyy institut russkogo yazyka im. A.S. Pushkina [Pushkin State Russian Language Institute]. Moscow, $1999.59 \mathrm{p}$.

Collins. The Times English Dictionary \& Thesaurus. Glasgow, Harper Collins, 2000. 1397 p.

Cowie A.P. English Dictionaries for Foreign Leaners: History. Oxford, Clarendon Press, 1999. 232 p.

Illustrated Oxford Dictionary. Oxford, Oxford University Press, 2000. 1008 p.

The New Encyclopedia Britannica. In 29 vols. Chicago, Auckland, London, Madrid, Manila, Paris, Rome, Seol, Sydney, Tokyo, Toronto, 19931994.

Onions C.T., Friedrichsen G.W.S., Burchfield R.W. eds. The Oxford Dictionary of English etymology. Oxford, Clarendon Press, 1996. 1040 p.

Crowther J., 1999. Oxford Guide to British and American Culture. Oxford, Oxford University Press. 600 p.

\section{Information about the Authors}

Alexander S. Mamontov, Doctor of Sciences (Philology), Professor, Department of Russian Literature and Intercultural Communication, Pushkin State Russian Language Institute, Akademika Volgina St., 6, 117485 Moscow, Russia, as-mamontov2@yandex.ru, https://orcid.org/0000-0002-6703-637X

Enkhtuyaa Tsedendorzhiyn, Doctor of Sciences (Philology), Director of Institute of Cognitive Linguistics, Seula St., 17, Ulaanbaatar, Mongolia, tuyana116@gmail.com, https://orcid.org/0000-0002-3965-8016

Vera V. Boguslavskaya, Doctor of Sciences (Philology), Associate Professor, Professor, Department of Russian Literature and Intercultural Communication, Pushkin State Russian Language Institute, Akademika Volgina St., 6, 117485 Moscow, Russia, boguslavskaya@gmail.com, https:/orcid.org/0000-0003-4118-382X

\section{Информация об авторах}

Александр Степанович Мамонтов, доктор филологических наук, профессор, профессор кафедры русской словесности и межкультурной коммуникации, Государственный институт русского языка им. А.С. Пушкина, ул. Академика Волгина, 6, 117485 г. Москва, Россия, as-mamontov2@yandex.ru, https://orcid.org/0000-0002-6703-637X

Энхтуяа Цэдэндоржийн, доктор филологических наук, директор Института когнитивной лингвистики, ул. Сэула, 17, Улан-Батор, Монголия, tuyana116@gmail.com, https:/orcid.org/0000-0002-3965-8016

Вера Васильевна Богуславская, доктор филологических наук, доцент, профессор кафедры русской словесности и межкультурной коммуникации, Государственный институт русского языка им. А.С. Пушкина, ул. Академика Волгина, 6, 117485 г. Москва, Россия, boguslavskaya@gmail.com, https://orcid.org/0000-0003-4118-382X 